\title{
The Information Security Specialty Reform for Undergraduate Education
}

\author{
Lian Wang
}

\begin{abstract}
The information security professional education has been pushed to a new height of national strategy. However some aspects, such as information security professional training model, personnel cultivating program and practical teaching system etc. still expose problems for undergraduate education. In this paper the problems existed have been analyzed, and the specific measures to improve the training model and the personnel cultivating program etc. have been proposed. Furthermore the practice teaching system reform measures are presented to improve final information security professionals' quality. Measures, such as teaching practice adjustment and practice teaching process reform, are recommended. Taking the information security specialty education reform is necessary to cultivate the information security professionals to meet the social requirements.
\end{abstract}

Index Terms-Information security, training model, personnel cultivating program, practical teaching system.

\section{THE CURRENT SITUATION OF INFORMATION SECURITY DISCIPLINE DEVELOPMENT}

Information security discipline development has made the remarkable achievements, but the following three aspects problems are still remained: Firstly, the traditional professional courses are overlapped too much. Great attentions are paid on learning the basic theory, and Information Security interdisciplinary in the current teaching model [1]. Based on questionnaire statistics of graduate status and professional demand of the Information Security, an analysis on the requirements for Information Security practitioners is made in 322 units. Network Security, Network and Communication, Password Knowledge and Mathematical Foundation, are the top four. And nearly two-thirds of the units are required those four fields. It is corresponded with the training schemes that "learning Information Security Theory and Technology first, give consideration of learning communications, and enhancing mathematics, physics, and law". But in concrete implement, the compulsory courses and computer science and technology are overlapped too much, the details are the curriculum standards, teaching material and teaching practice [2]. Secondly, the training method is too single. It failed to develop the students' ability according to

Manuscript received September 26, 2015; revised March 18, 2016. This work is supported by Chong Qing Higher School Teaching Research Reform Projects (Grant No. 143004, 141010, 133178), Program for Innovation Team Building at Institutions of Higher Education in Chongqing (Grant No. KJTD201310), and Chongqing University of Posts and Telecommunications Education Teaching Reform Project (XJG1515).

Lian Wang is with College of Computing Science and Technology, Chongqing University of Posts and Telecommunications, Chongqing 400065, P. R. China (e-mail: wanglian@cqupt.edu.cn). their characteristics, so it could not reach the target that is expert in one thing and good at many [3], [4]. Thirdly, the experimental courses are mainly verification experiments, few comprehensive design experiments are to cultivate and develop the students' creative idea and independent experiment capacity [5], [6].

\section{INFORMATION SECURITY PROFESSIONAL TRAINING MODEL REFORMATION AND THE PERSONNEL CULTIVATING PROGRAM IMPROVEMENT}

On the premise of the above factors, combined with the present situation of Information Security professionals training, the objectives of talents training are rearranged, and the available professional talent training scheme is improved and perfected, the cultivation process and approaches are brought new idea, furthermore the teaching, the practical teaching link and the content are improved.

\section{A. Information Security Specialty Orientation}

Recognize the professional characteristics and the knowledge structure, and relocate the training objectives based on characteristic of multidisciplinary characteristic of Information Security. Further clarify the Information Security specialty that is aimed at training senior technical personnel engaged on Information Security research, application, development, management and so on. Meanwhile, the political quality requirements of information security are the knowledge of law and management, the combination of theory and practice, the integrity characteristic. Thus, when training program is put emphasis on the Information Science and Technology basics, Information Security professional basic, general education and practical teaching should be strengthened, and the rational proportion of the Mathematical Basis, Communications Infrastructure, Computer Software and Hardware Infrastructure, Information Security Infrastructure and Information Security Management should be taken into account [7].

\section{B. Current Professional Training Scheme Improvement}

Since 2001, Information Security has developed a set of specialized course system of Information Security and teaching program, and the training program has been revised three times. In the revised training scheme, the curriculum teaching program follows the principle "multi disciplinary, fewer but better" and "to learn and not learn". To show the fundamental function of the hardware system, in addition to conventional hardware courses, for example "Large Scale Integrated circuit", "Smart Card Technology", "Electromagnetic Protection and Physical Security", 
"Embedded Systems" should be put more efforts on. To reflect the importance of Codes and Network Security, the related courses, such as "Cryptography", "Network Security", "Network Management", and "Network Programming" should be set. To adjust the professional basic compulsory course, some specialized elective courses should be translated to the specialized courses, such as "Computer Virus", "Information Hiding", and "Smart Card Technology" [8].

\section{C. ' $3+1$ ' Teaching Model Cultivation and Implementation}

Open the Information Security undergraduate process based on " $3+1$ " teaching mode. Namely, complete the four-year-course during three years. Students can take full use of the last year to complete graduation program and graduation practice. And the students that are excused from an examination to study for the master degree can take part in the supervisor's project group directly and bring forward the postgraduate studies and research. To the student who're preparing for taking a job, they can be arranged to employers or internship base. This mode can integrate social resources to talents training in colleges. With the help of industry and technology development, it can directly drive the teaching content reform and the training model innovation. And realize talents training connect seamlessly with social requirements, and finish the role transition training from students to professional. Furthermore makes students adapt to the tough competition of employment [9].

\section{REFORM PRACTICE TEACHING SYSTEM}

Information security, as a brand new specialty which has combined with comprehensiveness, practicalness and intersectionality compared with other traditional specialty. Experimental teaching side is not mature, which needs constantly explore and innovate.

\section{A. Adjust Teaching Practice Proportion}

The original information security practical teaching is divided into two parts: basic verification experiment and comprehensive design experiment, the proportion of their course hours is $70 \%$ and $30 \%$ individually. The proportion of the verification experiment is heavy, which certainly will restrain student's professional innovation ability cultivation. Therefore, after adding the part of research and innovative experiment, the practice teaching will be adjusted as three parts, and also increase the proportion of the latter parts, to cultivate and improve student's comprehensive thinking and innovation ability. Basic verification experiment is about $40 \%$ of the total class hours, which is linked up with the theory course content, and relatively fixed. Comprehensive design experiment requires students to comprehensively apply what they learn from more than one course. Designed for the specific problems, improve the comprehensive design ability. This experiment level mainly consists of the curriculum design, training on the training platform, and actual combat training in Practice base, etc. The comprehensive design experiment is about $40 \%$ of the total class hours. Innovative experiment requires students to apply what they learned to the creative design for innovation subject. The next experiment level is included of innovative research, graduation design and graduation thesis, contests, etc... Research and innovative experiment is about $20 \%$ of the total class hours, and updated every year.

\section{B. Improve Information Security Practice Content}

Construct "Attack-Defense-Evidence" triangle support information security practical content. Construct "Attack-Defense-Evidence" triangle support information security practical content, which is tight with the core technology. "Attack-Defense-Evidence" triangle support information security practical content system reform takes network attacks, network security defense and computer evidence as the core, and tightly relate with information security professional practical ability. Abandon "anti-virus", "firewall" and "intrusion detection" these "three old ones" practical content system. The content system emphasizes on the "evidence" practical ability, follows the information security technology development, refines the information security professional characteristics, and shows the feature that information major takes importance of practice and innovation. At the same time, it coincides to the national emergency information security talent training. In this scientific practical teaching model, the excellent is successful from "curiosity and emulation".

"Attack-Defense-Evidence" triangular support information security practical content system includes: Network attacks practice, which makes students fully learn the architecture of network attack model, understanding network attacks principle, master representative attack tools, apply different attack techniques and tools to design network attack plan and implementation of network attacks. Secondly, network defense practice makes students master the corresponding defense system establishment method and anti-attack technology. Computer evidence practice, make students know well the basic technology of computer evidence technology, make them master of hardware and software tools of common computer evidence, which can copy and recover suspicious data in computer, and analyze comprehensively and record accurately, and finally present test results. The system highlights the practical content of information security content system structure, making the practice more systematic and standardized. Let students truly understand the overall framework of information security and grasp the core technology of security technology.

\section{Construct Multilevel Information Security Practice Educational System}

That "experiment, internships, training and actual combat" is organized architecturally is the core and the highlight of information security practice teaching system. The system is mainly divided into four layers, carries out the practical activities in spiral recursive type.

"Experiment and Internship" practical activity is carried out among all information security professional students, "training and actual combat" practical activity is developed according to multiple mechanisms, such as student ability and interest to select and organize to excavate students' potential maximally.

"Experiment" practice activity mainly includes "in-class experiment", "curriculum project", and "comprehensive 
experiment" "Internship" practical activities mainly include graduation internship, enterprises internship and so on. "Training" practical activities includes selection students to the domestic well-known training center to train and so on. "Actual combat" practical activity includes all kinds of internal and external competition, and the actual product development and scientific research projects, for example, internal information security contest, the National Information Security Competition, ACM Programming Contest, database applications contest, National Mathematical Modeling Contest, Microsoft Imagine Cup and so on. Meanwhile, the students participate in security product development, site security reinforcement, websites and BBS public opinion monitoring and analysis, electronic forensics identification of actual cases and other combat activities to further enhance students' practical capacity [10], [11].

\section{Reform Practice Teaching Process}

"Basic verification experiment, comprehensive design experiment, research and innovation experiment", on the realization method of this teaching experiment level, basic verification type teaching was arranged at recess time. Comprehensive design experiment will be arranged after the completion of theory lessons, and then concentrative practice is in one week or two weeks. The content of research innovative experiment comes from teacher's scientific research project, the student's independent scientific research topics, social practice activities and enterprise application requirement. Therefore its experimental content is changed every year. Innovative experiment's style and content can be diverse, not only can be combined with teacher's scientific research project, but also can be carried out through college student's amateur scientific research project, competitive program, and interest groups, etc.

Reference to engineering education standards, combine social employment required, reform engineering practical education [9]. First, take teachers' latest scientific and technological achievements to enrich course content and integrate with the knowledge available, which can help students to know the most cutting-edge scientific knowledge timely. Second, let students master interdisciplinary knowledge. In the traditional engineering education system in our country, the different disciplines are closely guarded. Therefore the reform is needed to break the boundaries between various disciplines, inject interdisciplinary knowledge, strengthen the integration of many courses, and design interdisciplinary courses and integrated curriculum.

All courses should build a platform of combineing theoryandpracticeby applying theory into practice, which is the fundamental requirement to cultivate students' engineering practical ability. In addition, for each course, especially engineering courses teaching, besides emphasize the basic subject knowledge, we should consistently enrich the engineering cases into the course content. In the professional education aspect, multistep cultivation scheme which consists of engineering consciousness, engineering personality and engineering ability is adopted. During the engineering consciousness cultivation phase, emphasize curriculum arrangement corresponding to the formation and development of knowledge capacity, and motivate students' potential engineering awareness. During the engineering personality formation phase, strengthen the corporation with well-known domestic and abroad enterprises. Take the mutual practice between enterprises and universities as main part and focus on the effectiveness of engineering personality. During the engineering ability forging phase, use the evaluation result of ability quantification as feedback index, rationally plan training method and accelerate the engineering ability speed, professional cultivation ideas as shown in Fig. 1.

According to different fields, professional practical ability can be divided into several parts: software practical ability field, hardware practical ability field, cryptography practical ability field, network security practical ability field, computer forensic practical ability field and innovation practical ability field. The overall structure of the application-oriented information security professional practical ability system is shown in Fig. 2. Practical ability system uses practical teaching system to cover, use practical teaching system to cultivate and improve students' practical ability. Practical teaching system consists of all kinds of practical teaching links; and practical ability system can have different coverage ways, so different practical teaching systems are available.

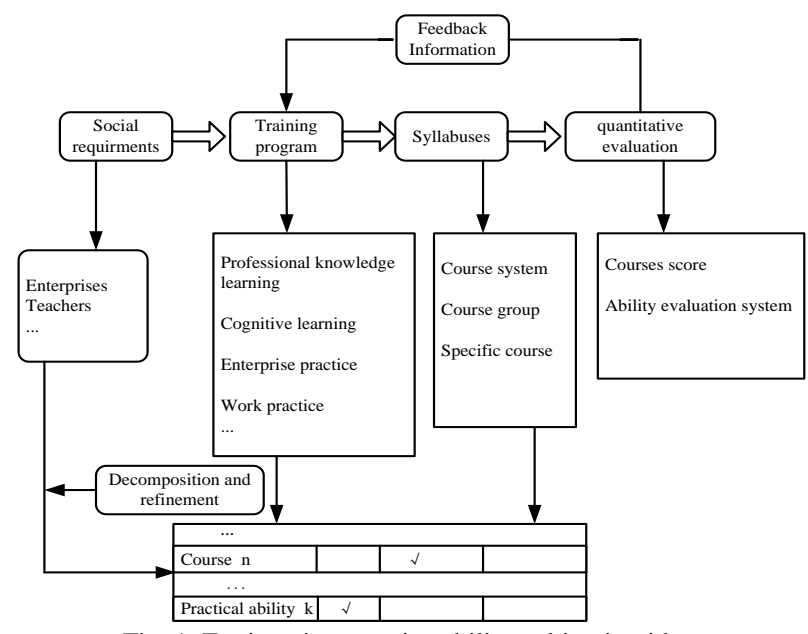

Fig. 1. Engineering practice ability cultivating idea.

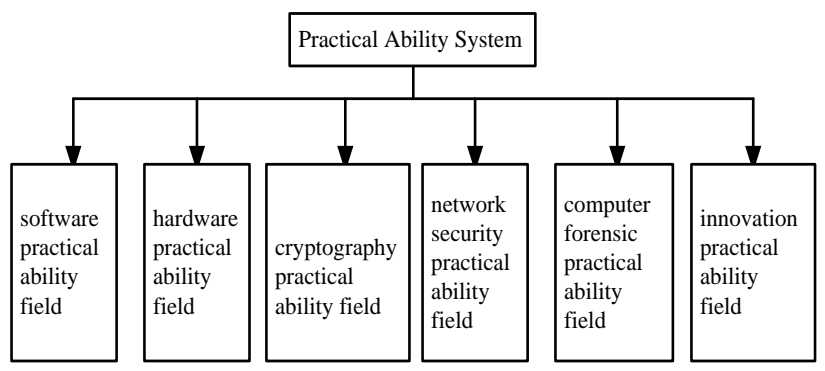

Fig. 2. Practical ability system structure.

\section{E. Increase Inside and Outside School Training Base Input}

The operation of the school training base is reflected in the following three aspects.

Firstly, laboratory is fully opened for students, encourage students to carry out amateur scientific research, and do some public academic report and discussions to show students' amateur research. Students' research products will be open exhibition and awards, and be rewarded innovate credit, to inspirit the enthusiasm of students to participate in scientific 
research.

Secondly, computing science school, national key laboratory of software engineering, national engineering research center for multimedia software and other powerful scientific research strength can not only provide a large number of high-quality teachers, but also provide a large number of cutting-edge issues for students and train them.

Thirdly, build innovative experimental base organized by college, including ACM international collegiate programming contest training base, computer simulation contest, embedded system competition training base, and Information security training group, etc. All of these provide the experimental conditions and places for students to study independently, improve their ability of solving practical problems. Teaching and practice bases outside school is the important place to carry out the basic practice teaching task, and to cultivate students' practical ability, innovative spirit and entrepreneurial ability. A part of our college students are selected to the relevant enterprises to carry out the social practice, and set the professional course which is relate to the enterprise projects engaged, to deepen the theory understanding in practice, and grasp basic practical skills in their enterprise application platform. It can not only solve the problem of production of the enterprise, but also can cultivate the students' practical competent and innovation ability through this measure. At the same time, we also have signed an ordering training protocol with the key IT enterprises, to achieve employment and practice directly.

\section{F. Expand Information Security Large Enterprise Cloud Platform, School and Enterprise Cooperation Platform, and Enrich Professional Practice Platform}

By researching information security recruitment market , as well discussing with security enterprises employing department, overall considering the multiple needs of employment, classify graduation tendency into continue research, developing engineer, network security engineer, security test engineer and other targets. Then based on different targets to extract engineering ability index, establish a matrix which can reflect the relationship between courses and ability and establish professional practical platform plan which can adapt to the current industry development. Information security practice comprehensive platform can reflect information security system architecture and cover the comprehensive experimental platform of typical experimental system. According to "experiment, internship, training, practice" is layered teaching system, spirally carry out practical activities. Specifically, experiment and internship should cover all information security students. According to students' ability, interest and other factors, training and practices are organized and selected to maximize exploring the students' potential.

\section{CONCLUSION}

Multilevel information security practice teaching system follows the law of education regular, pay attention to the differentiation of practice group and the individualized personality development, which provides scientific guidance for students to carry out practical activities. Highlight the important role and the organic connection of "attack" and "defense". The reform of information security practical content should tightly relate with the kernel technology of information, highlight the framework of system architecture to make the practical content more systematical and more standard. Cultivating college students' innovation spirit, practice ability and entrepreneurship are the important part in higher education. Timely adjust and update personnel training mode of information security professional, and enhance the level of practice teaching, which are the assurance to further improve this professional teaching quality and enhance students' social professional quality and employment competitiveness.

\section{ACKNOWLEDGMENT}

I would like to thank Prof. Xia Ying and Prof. Chen Long meaningful suggestions and unselfish help.

\section{REFERENCES}

[1] S. U. Ting-Bo, "Teaching reform of network and information security course for network engineering specialty," Computer Knowledge \& Technology, 2014.

[2] H. E. Xiping and H. Jiang, "Educational reform and innovation for undergraduate in computer specialty," Computer Education, 2011.

[3] Y. Wang, L. Z. Zhao, and W. H. Zhang, "Discussion of the training of information security specialty personnel exploration ability," Netinfo Security, 2011.

[4] F. U. Jie, Y. U. Li, and W. U. Li-Bing, "Establishing the talent cultivating pattern of information security specialty and its practice teaching reform," Sci-Tech Information Development \& Economy, 2009.

[5] Y. X. Lai and Z. Yang, "Developing new information security experiments in basic network laboratory," Computer Education, 2010

[6] H. R. Cheng et al., "Research on the teaching of synthetic experiments on information security," Experiment Science \& Technology, 2011.

[7] G. Z. Sun, W. Chen, and W. Zhang, "Discussion on specialty construction of information security," Computer Education, 2010.

[8] X. J. Wang, S. L. Liu, and Q. R. Huang, "Exploration and construction of practice teaching system of information security specialty," Journal of Hangzhou Dianzi Universitz, 2011.

[9] F. Liu, "Innovation path research on the information security teaching based on the engineering practice innovation," Journal of Hubei Correspondence University, 2015.

[10] Y.-X. Lai et al., "Exploration on promoting method of project ability for information security specialty," Experimental Technology \& Management, 2013.

[11] H. Zhang and I. Institute, "Exploration on the practical teaching system in undergraduate specialty of information security," Office Informatization, 2014.

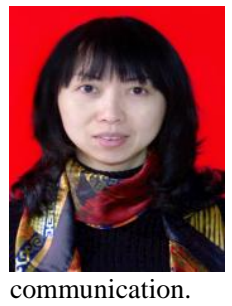

Lian Wang received the M.S. degree in computer and network engineering from London South University, London, UK, in 2004. And she is currently a Ph.D. candidate at Southwest Jiaotong University, Chengdu, China. She is an associate professor in the College of Computer Science and Technology, Chong Qing University of Posts and Telecommunications. Her research interests include network coding and wireless

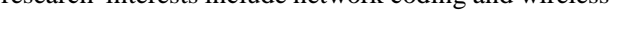

